\title{
Preparation and Characterization of Superabsorbent Polymer (SAP) by Graft Polymerization of Carboxymethyl Cellulose
}

\author{
A.B.M. Nazmul Islam ${ }^{1, a *}$, Md. Anisul Islam ${ }^{2, b}$ \\ ${ }^{1}$ Daffodil International University, Dhaka, Bangladesh \\ ${ }^{2}$ Department of Applied Chemistry and Chemical Engineering, Rajshahi University, Rajshahi, \\ Bangladesh \\ a*nazmul.acce.26@gmail.com, ${ }^{\mathrm{b}}$ anisul@turagbd.com
}

Keywords: Carboxymethyl cellulose, superabsorbent polymers (SAP), ceric ammonium nitrate, acrylamide monomer and degree of swelling.

\begin{abstract}
The synthesis of superabsorbent polymer withCarboxymethyl cellulose using ceric ammonium nitrate (CAN) initiated acrylamide (AA) monomer through asolution based graft copolymerization has been conducted. The characterizing studies were performed using Fourier transform infrared (FTIR) spectroscopy, Atomic force microscopy (AFM) and swelling studies. FTIR spectra established crosslinked polymeric network structure of hydrogels through graft copolymerization reaction between CMC and acrylamide indicating incorporation of acrylamide monomer resulting the formation of carboxamide group $(>C=O)$. AFM showed the surface morphology or properties of superabsorbent. The hydrophilic properties of the superabsorbent were identified by the swelling percentage or degree of swelling.
\end{abstract}

\section{Introduction}

Superabsorbent polymers (SAPs) (also called slush powder) are polymers that can absorb and retain extremely large amounts of a liquid relative to their own mass [1]. These polymers, when cross-linked, absorb aqueous solutions through hydrogen bonding with water molecules [2]. Owing to their unique physico- chemical properties, SAPs have been found showing extended absorption capacity, swelling behavior and permeability. These coupled with surface properties, optical properties and mechanical properties make them promising materials for a wide variety of applications [3]. As a result, superabsorbents are widely used in many fields, such as agricultural and horticultural, disposable diapers, feminine napkins, pharmaceuticals, textile and medical applications [4] and [5]. Carboxymethyl cellulose is a derivative of cellulose obtained by the chemical modification of natural cellulose [6].

In present work an endeavor has been taken to modify the properties of Carboxymethyl cellulose (CMC) gels by graft copolymerization with Acrylamide monomer to form super absorbent polymer (SAP), followed by subsequent study of the properties of the SAP so prepared.

\section{Materials and methods}

\section{Materials}

Carboxymethyl Cellulose Sodium salt was purchased from BDH Chemicals Ltd. Poole, England. Acrylamide monomer and Ceric Ammonium Nitrate was purchased from Loba Chem. Pvt. Ltd. Mumbai, India.Acetone was obtained from Merck, Germany. Potassium bromide was obtained from Sigma ultra, USA.

\section{Methods}

\section{Preparation ofsuperabsorbent polymer (SAP)}

Acrylamide monomerand ceric ammonium nitrate were dissolved in water separately. A modifying bath for CMC was prepared by adding required percentage of a monomer $(60 \%$ acrylamide on the basis of CMC) and Initiator (20\% ceric ammonium nitrate on the basis of 
CMC). Freshly prepared solution of ceric ammonium nitrate and acrylamide were added subsequently to the reaction mixture of $\mathrm{CMC}$ with constant stirring with 1: 50 sample liquor ratio. Modification of $\mathrm{CMC}$ was carried out at temperature $65^{\circ} \mathrm{C}$ for $90 \mathrm{~min}$ with occasional stirring and then allowed for further $30 \mathrm{~min}$ as the bath cools down [7] and [8].

\section{Extraction of homopolymer from preparedsuperabsorbent polymer (SAP)}

The product was purified by extracting the homopolymer of polyacrylamide (that might be produced during the polymerization) from the crude product by washing with acetone-water mixture (30:70), followed by acetone washingand air drying for $24 \mathrm{~h}$ at room temperature[9].

\section{Determination of degree of swelling of superabsorbent polymers (SAP)}

After extraction the sample was dried to a constant weight for $24 \mathrm{~h}$ [10] and [11]. Degree of swelling (DS)

$$
\mathrm{DS}=\left(\mathrm{W}_{\mathrm{t}}-\mathrm{W}_{0}\right) / \mathrm{W}_{0}
$$

where $\mathrm{W}_{\mathrm{t}}$ is the weight of swelling superabsorbent polymer (SAP) after soaking time, $\mathrm{W}_{0}$ is the initial weight of dry polymer.

\section{Determination of water desorption of superabsorbent polymer (SAP)}

The prepared hydrogel samples were weighted initially and then placed in an open environment for water desorption. At every $1 \mathrm{~h}$ interval the weight of the samples were taken for the first four hours and it was continued after 24, 48 and $72 \mathrm{~h}$ until constant weight is established. Finally, the percentage of water desorption was calculated gravimetrically at room temperature and average humidity was $50-55 \%$, respectively [12]. Water desorption

$$
\mathrm{WD} \%=\left[\left(\mathrm{W}_{0}-\mathrm{W}_{\mathrm{t}}\right) / \mathrm{W}_{0}\right] * 100
$$

where, $\mathrm{W}_{\mathrm{t}}$ is the weight of the dry superabsorbent polymer (SAP) after air drying time, $\mathrm{W}_{0}$ is the weight of the prepared superabsorbent polymer (SAP).

\section{Determination of water absorption of superabsorbent polymer (SAP)}

Gel samples after extraction of sol, were dried to a constant weight and immersed in distilled water at room temperature. Gel swells in water. At first, weight of swelled gel was taken for the first four hours and it was continued after 24, 48 and $72 \mathrm{~h}$. After completion of absorbing period, the hydrogels were taken out and then the adhering solvent (water) was removed using tissue paper. The hydrogel is then weighted as quickly as possible [11]. Finally, the percentage of hydration or water absorption was calculated gravimetrically as, Water absorption

$$
\mathrm{WA} \%=\left[\left(\mathrm{W}_{\mathrm{t}}-\mathrm{W}_{0}\right) / \mathrm{W}_{0}\right]^{*} 100
$$

where, $\mathrm{W}_{\mathrm{t}}$ is the weight of the swelling superabsorbent polymer (SAP) after soaking time, $\mathrm{W}_{0}$ is the weight of the dry superabsorbent polymer (SAP).

\section{Results and discussion}

\section{FTIR Observation}

The grafting of superabsorbent polymer (SAP) is confirmed by comparing FTIR spectra of pure carboxymethyl cellulose and the polymer so prepared. Fig 1. (a) shows the FTIR spectra of pure caboxymethyl cellulose. The spectrum showed peak at $3391 \mathrm{~cm}-1$ due to the stretching of $-\mathrm{OH}$ group of Carboxylic acid. The peak at $2922 \mathrm{~cm}-1$ indicates dimer $-\mathrm{OH}$ stretching vibration of Carboxylic acid. The peak at $1595 \mathrm{~cm}-1$ indicated $>\mathrm{C}=\mathrm{O}$ stretching vibrations due to the presence of carboxylate (asymmetric). The peak at $1417 \mathrm{~cm}-1$ and $1325 \mathrm{~cm}-1$ could be assigned to $\mathrm{CH} 2$ and $\mathrm{CH} 3$ bending modes of alkanes respectively. The peak at $897 \mathrm{~cm}-1$ and $710 \mathrm{~cm}-1$ suggested the presence of alkenes $=\mathrm{C}-\mathrm{H}$ stretching. The peak at $604 \mathrm{~cm}-1$ suggested the presence of alkynes of C$\mathrm{H}$ bending. 
Fig 1. (b) shows the FTIR spectra of carboxymethyl cellulose-g-acrylamide hydrogel. The peaks at $3435 \mathrm{~cm}-1$ indicated -NH stretching of amide. The characteristic peak at $1636 \mathrm{~cm}-1$ was due to the amide-I band of carboxamide group ( $>\mathrm{C}=\mathrm{O}$ stretching vibration frequency). The presence of a band at $1400 \mathrm{~cm}-1$ was due to carboxylate (symmetric). The peak at $612 \mathrm{~cm}-1$ suggested the presence of alkynes of $\mathrm{C}-\mathrm{H}$ bending. By comparing the spectrum of superabsorbent polymer (SAP)with pure carboxymethyl cellulose, some new absorption bands are observed in addition to characteristic hydrogel absorption bands. The existence of a rather sharp intense peak at $1636 \mathrm{~cm}-1(\mathrm{C}=\mathrm{O}$, carboxamide group $)$ in IR spectra of the graft copolymers is a certain evidence of grafting [13]. Most of the other peaks of superabsorbent polymer (SAP) are related to pure carboxymethyl cellulose with the functional groups. So the presence of appreciable amounts of carboxamide groups in reaction product after extraction is the proof for grafting of acrylamide onto carboxymethyl cellulose producing superabsorbent hydrogel.

Table 1: Characteristic FTIR peaks shows by superabsorbent polymer (SAP)

\begin{tabular}{|l|l|l|}
\hline Functional groups & Absorption $\left(\mathrm{cm}^{-1}\right)^{\mathrm{a}}$ & Absorption $\left(\mathrm{cm}^{-1}\right)^{\mathrm{b}}$ \\
\hline Carboxylic acid & $2800-3400$ & 2922,3391 \\
\hline Carboxamide & $1630-1690$ & 1636 \\
\hline Carboxylate (symmetric) & $1400-1465$ & 1400 \\
\hline Carboxylate(asymmetric) & $1525-1595$ & 1595 \\
\hline Amide & $3400-3500$ & 3435 \\
\hline
\end{tabular}

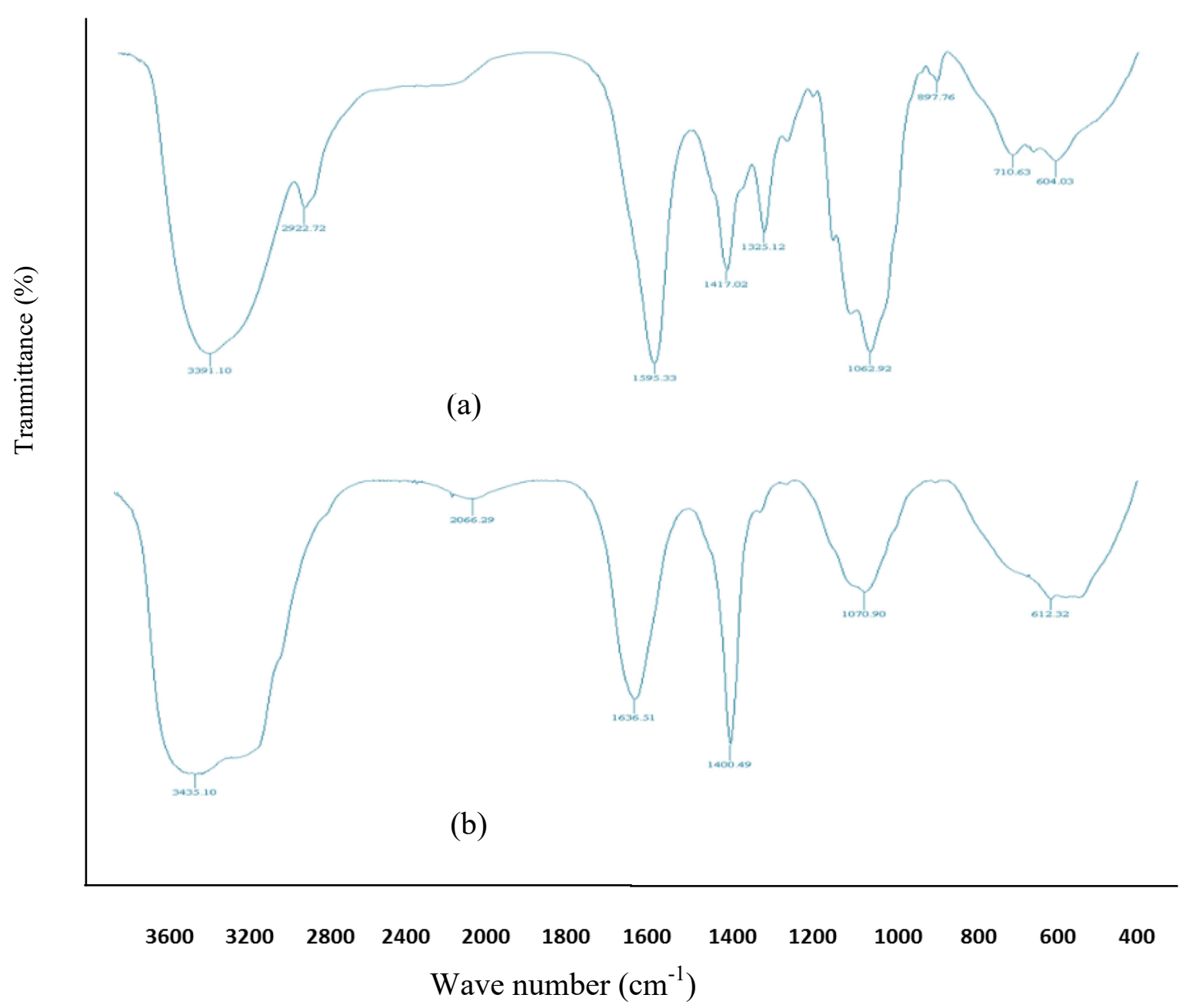

Figure 1: (a) FTIR transmittance spectra of pure carboxymethyl cellulose (b) superabsorbent polymer (SAP) 


\section{AFM analysis}

Atomic force microscopy is commonly used for determining the surface properties of the hydrogel. AFM is performed using a cantilever. As the cantilever passes over surface just touching the tip it experiences fluctuation due to presence of pores in hydrogels, giving rise characteristics amplitude and phase. As the Fig 2. (a) and Fig 2. (b) show the AFM images in terms of amplitude of pure carboxymethyl cellulose. Fig 3. (a) and Fig 3. (a) show the AFM images of superabsorbent polymer (SAP) prepared in our laboratory. The surface of pure carboxymethyl cellulose is showing the presence of regular building blocks (BB) of sizes $\sim 1-2 \mu \mathrm{m}$. The shapes of the building blocks are irregular with no visible pores. The surface morphology of the superabsorbent polymer (SAP) reveals the presence of sub-micron building blocks (SBB) with visible pores on the surface. The presence of visible pores reveals the proof of superabsorbent [14].

(a)

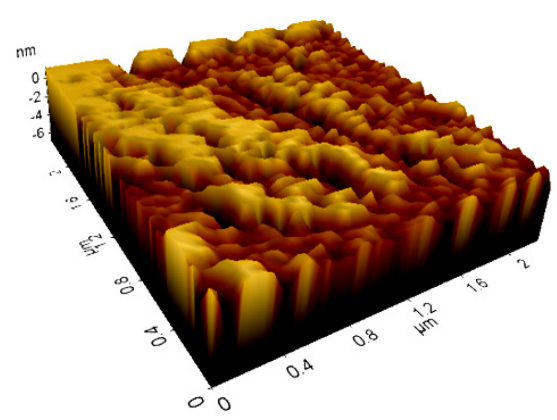

(b)

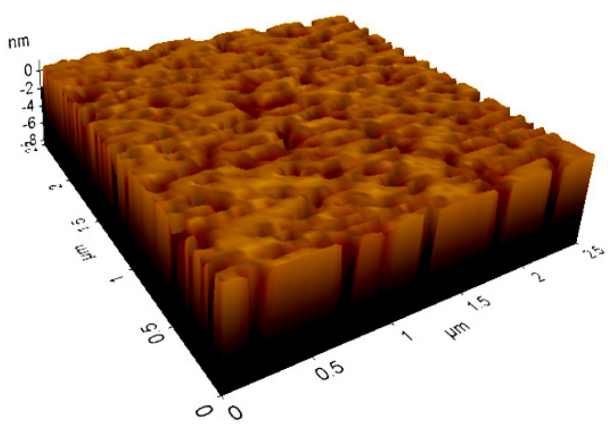

Figure 2: (a) Amplitude of pure carboxymethyl cellulose (b) Amplitude of superabsorbent polymer (SAP)

(a)

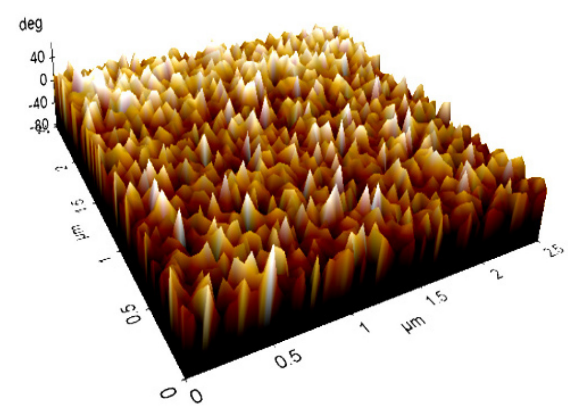

(b)

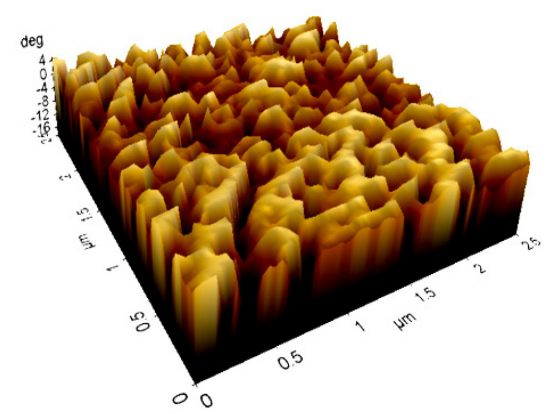

Figure 3: (a) Phase of pure carboxymethyl cellulose and (b) Phase of superabsorbent polymer (SAP)

\section{Swelling and Shrinkage Study}

Table- 4. shows, the water desorption of superabsorbent polymer (SAP) increased with the increase of air drying time. A regular increase is observed upto 12 hour. But, after this period, no remarkable desorption of superabsorbent polymer (SAP) was observed as the test continues upto $72 \mathrm{hrs}$ with constant water desorption and it is seen the desorption in superabsorbent polymer (SAP) increases drastically initially and after $24 \mathrm{~h}$ it becomes stable. After this time no more desorption was occurred. It can be concluded that the gel has no ability to contain its unbounded water.

Water absorption of superabsorbent polymer (SAP) has been conducted and it is seen swelling of hydrogel takes place as the times pass by. A regular increase is observed upto 12 hour. But, after this period, no remarkable absorption of superabsorbent polymer (SAP) was observed as the test continues upto $72 \mathrm{hrs}$ with constant water absorption and it is seen the absorption in superabsorbent polymer (SAP) increases drastically initially and after $24 \mathrm{~h}$ it becomes stable. After this time no more absorption was found and it is said the hydrogel is saturated with water. 
Table 2: Determination of degree of swelling of superabsorbent polymer (SAP)

\begin{tabular}{|l|l|l|l|l|}
\hline $\begin{array}{l}\text { Number of } \\
\text { sample }\end{array}$ & $\begin{array}{l}\text { Weight of the } \\
\text { dry gel, } \mathrm{w}_{0}(\mathrm{~g})\end{array}$ & $\begin{array}{l}\text { Weight of the swelling } \\
\text { hydrogel after soaking } \\
\text { time, } \mathrm{w}_{\mathrm{t}}(\mathrm{g})\end{array}$ & $\begin{array}{l}\text { Degree of } \\
\text { swelling, ds }=\left(\mathrm{w}_{\mathrm{t}}\right. \\
\left.-\mathrm{w}_{0}\right) / \mathrm{w}_{0}\end{array}$ & $\begin{array}{l}\text { Average degree } \\
\text { of swelling }\end{array}$ \\
\hline Batch 1 & 0.17 & 1.08 & 5.35 & \multirow{2}{*}{5} \\
\hline Batch 2 & 0.19 & 1.16 & 5.10 & 5.24 \\
\hline Batch 3 & 0.15 & 0.94 & 5.26 & \\
\hline
\end{tabular}

Table 3: Determination of water desorption of superabsorbent polymer (SAP)

\begin{tabular}{|l|l|l|l|l|}
\hline $\begin{array}{l}\text { Number of } \\
\text { sample }\end{array}$ & $\begin{array}{l}\text { Weight } \\
\text { Of the prepared } \\
\text { hydrogel, } \mathrm{w}_{0}(\mathrm{~g})\end{array}$ & $\begin{array}{l}\text { Weight of the dry } \\
\text { hydrogel after air } \\
\text { drying time, } \mathrm{w}_{\mathrm{t}}(\mathrm{g})\end{array}$ & $\begin{array}{l}\text { Percentage of water } \\
\text { desorption, wd } \%= \\
{\left[\left(\mathrm{w}_{0}-\mathrm{w}_{\mathrm{t}}\right) / \mathrm{w}_{0}\right]^{*} 100}\end{array}$ & $\begin{array}{l}\text { Average } \\
\text { percentage of } \\
\text { water } \\
\text { desorption }\end{array}$ \\
\cline { 1 - 4 } Sample 1 & 1.02 & 0.15 & 85 & \multirow{2}{*}{86} \\
\cline { 1 - 2 } & 1.13 & 0.18 & 84 & 89 \\
\hline Sample 3 & 1.17 & 0.13 & 89 & \\
\hline
\end{tabular}

Table 4: Interaction of superabsorbent polymer (SAP) with water

\begin{tabular}{|l|l|l|l|l|l|l|l|}
\hline \multirow{2}{*}{$\begin{array}{l}\text { Super Absorbent } \\
\text { Polymer (SAP) }\end{array}$} & \multicolumn{7}{|c|}{ Time (hr) } \\
\cline { 2 - 9 } & 1 & 2 & 3 & 4 & 12 & 24 & 72 \\
\hline Water absorption (\%) & 55 & 92 & 194 & 208 & 524 & 524 & 524 \\
\hline Water desorption (\%) & 10 & 19 & 30 & 42 & 86 & 86 & 86 \\
\hline
\end{tabular}

\section{Conclusions}

In this work, an approach have been taken for preparing superabsorbent polymer (SAP) by a simple chemical route with a high holding and absorbing water capacity. The surface properties are measured as a function of the tip deflection as it moves over the surface. In absence of visible pores in pure carboxymethyl cellulose superabsorbent polymer (SAP) reveals the presence of sub-micron building blocks (SBB) with visible pores on the surface. The hydrophilic properties of the hydrogels in terms of water absorbing capacity were due to the presence of visible pores in the superabsorbent polymers (SAP). In present work modified properties of Carboxymethyl cellulose (CMC) gels prepared by graft copolymerization with Acrylamide monomer will open up door for application in industrial sector after subsequent process optimization.

\section{References}

[1] K. Horie et al., Definitions of terms relating to reactions of polymers and to functional polymeric materials, Journal of Pure and Applied Chemistry. 76 (2004) 889-906.

[2] K. Kabiri, Synthesis of fast-swelling superabsorbent hydrogels: effect of crosslinker type and concentration on porosity and absorption rate, European Polymer Journal. 39 (2003) 13411348 .

[3] F.L. Buchholz, A.T. Graham, Modern Superabsorbent Polymer Technology, Elsevier, Amsterdam, 1997.

[4] L.B. Peppas, R.S. Harland, Absorbent Polymer Technology, Elsevier, Amsterdam, 1990. 
[5] A. S. Hoffman, J.C. Salamone, Polymeric Materials Encyclopedia; CRC Press, Boca Raton, FL, 1996.

[6] R. Bodvik et al., Aggregation and network formation of aqueous methylcellulose and hydroxypropylmethylcellulose solutions, Colloids and Surfaces A: Physicochemical and Engineering Aspects, 2008.

[7] M.H. Rafie et al., Grafting of methacrylic acid to loomstate viscose fabric using KMnO4/NaHSO3 system, Journal of Polymers and polymer composites. 2(2) (1994) 99-104.

[8] A. Hebeish, A. Katouch, M.H.I. EL-Rafie, Graft copolymerization of vinyl monomer with modified cotton. II. Grafting of acrylonitrile and methyl methacrylate on acetylated cotton, Journal of Applied polymer science. 15(1) (1971) 11-24.

[9] G.F. Fanta, Synthesis of graft and block copolymers of starch, Block and graft copolymerization. 1 (1973) 11.

[10] P. Liu et al., Radiation preparation and swelling behavior of sodium carboxymethyl cellulose hydrogels, Journal of Radiation Physics and Chemistry. 63 (2002) 525- 528.

[11] N. Nagasawa et al., Radiation crosslinking of carboxymethyl starch, Journal Of Carbohydrate Polymers. 58 (2004) 109-113.

[12] E. Valles et al., Equilibrium swelling and mechanical properties of hydrogels of acrylamide and itaconic acid or its esters, Polymer Bulletin. 44 (2000) 109-114.

[13] M.Sadeghi, M.N. Esmat, F. Shafie, Preparation, characterization, and optimization of grafting parameters, Academic Journals Scientific Research and Essays. 7 (2012) 511-521.

[14] K. Pal, A.K. Banthia, D.K. Majumdar, Polymeric Hydrogels: Characterization and Biomedical Applications - A mini review, Designed Monomers and Polymers. 12 (2009) 197-220. 